\title{
Article \\ Compliance, Adherence and Concordance Differently Predict the Improvement of Uremic and Microbial Toxins in Chronic Kidney Disease on Low Protein Diet
}

\author{
Andreana De Mauri ${ }^{1, *(D)}$, Deborah Carrera ${ }^{2}$, Matteo Vidali ${ }^{3}\left(\mathbb{D}\right.$, Marco Bagnati $^{4}$, Roberta Rolla ${ }^{4,5}$, \\ Sergio Riso ${ }^{2} \mathbb{D}$, Massimo Torreggiani ${ }^{6,+} \mathbb{D}$ and Doriana Chiarinotti ${ }^{1,+}$ \\ 1 Nephrology and Dialysis Unit, Maggiore della Carità University Hospital, 28100 Novara, Italy; \\ doriana.chiarinotti@maggioreosp.novara.it \\ 2 Nutritional Science and Dietetic, Maggiore della Carità University Hospital, 28100 Novara, Italy; \\ deborah.carrera@libero.it (D.C.); sergio.riso@maggioreosp.novara.it (S.R.) \\ 3 Clinical Chemistry Unit, Fondazione IRCCS Ca' Granda Maggiore Policlinico Hospital, 20122 Milano, Italy; \\ matteo.vidali@gmail.com \\ 4 Clinical Chemistry Laboratory, Maggiore della Carità University Hospital, 28100 Novara, Italy; \\ marco.bagnati@maggioreosp.novara.it (M.B.); roberta.rolla@med.uniupo.it (R.R.) \\ 5 Department of Health Sciences, Amedeo Avogadro University of Eastern Piedmont, 28100 Novara, Italy \\ 6 Néphrologie et Dialyse, Centre Hospitalier Le Mans, 72037 Le Mans, France; maxtorreggiani@hotmail.com \\ * Correspondence: andreanademauri@libero.it \\ + These authors contributed equally to this work.
}

check for

updates

Citation: De Mauri, A.; Carrera, D.;

Vidali, M.; Bagnati, M.; Rolla, R.; Riso,

S.; Torreggiani, M.; Chiarinotti, D.

Compliance, Adherence and

Concordance Differently Predict the

Improvement of Uremic and

Microbial Toxins in Chronic Kidney

Disease on Low Protein Diet.

Nutrients 2022, 14, 487. https://

doi.org/10.3390/nu14030487

Academic Editor: Vincent Lee

Received: 29 December 2021

Accepted: 21 January 2022

Published: 23 January 2022

Publisher's Note: MDPI stays neutral with regard to jurisdictional claims in published maps and institutional affiliations.

Copyright: (C) 2022 by the authors. Licensee MDPI, Basel, Switzerland. This article is an open access article distributed under the terms and conditions of the Creative Commons Attribution (CC BY) license (https:// creativecommons.org/licenses/by/ $4.0 /)$.

\begin{abstract}
Background. In medicine, "compliance" indicates that the patient complies with the prescriber's recommendations, "adherence" means that "the patient matches the recommendations" and "concordance" means "therapeutic alliance" between patient and clinician. While a low protein diet (LPD) is a cornerstone treatment of chronic kidney disease (CKD), monitoring the actual performance of LPD is a challenge. Patients. Fifty-seven advanced CKD adult patients were enrolled and LPD prescribed. Compliance was evaluated through the normalized protein catabolic rate (nPCR), adherence by the dietitian by means of a 24-h dietary recall and concordance by the nephrologist during consultations. Traditional parameters as well as total p-Cresyl Sulphate (t-PCS), total Indoxyl Sulphate ( $\mathrm{t}-\mathrm{IS})$ and Lipoprotein-associated phspholipase $\mathrm{A}_{2}$ (Lp-PLA $)$ were compared between adherent/not adherent and concordant/not concordant subjects at enrolment and after two months. Results. nPCR, blood urea nitrogen, cholesterol and triglycerides significantly decreased in all patients. t-PCS and t-IS decreased among adherent subjects. Lp-PLA $2, t-P C S$, free-PCS and t-IS decreased among concordant subjects, while these increased in non-concordant ones. Conclusion. This study demonstrates that LPD may improve the control of traditional uremic toxins and atherogenic toxins in "adherent" and "concordant" patients. A comprehensive and multidisciplinary approach is needed to evaluate the compliance/adherence/concordance to LPD for optimizing nutritional interventions.
\end{abstract}

Keywords: low protein diet; chronic kidney disease; compliance; adherence; concordance; p-cresol; indoxyl-sulphate; lipoprotein-associated phospholipase $\mathrm{A}_{2}$

\section{Introduction}

Advances in pharmacologic therapy in the last five decades has allowed for the stabilization, functional recovery and favourable outcomes in patients with chronic diseases, provided that they have to assume their therapies their entire life. In this context, a new challenge for clinicians is how to verify whether patients follow medical prescriptions. This is a very old issue: even Hippocrates recorded whether patients took their medications to monitor the effects of the therapy. Yet, recently, the medical terminology has been evolving and incorporating new concepts [1]. 
The terms "compliance", "adherence" and "concordance" are usually used as synonymous, but they indicate different ways of monitoring medical prescriptions.

As described by De las Cuevas, the word "compliance" firstly appeared in the English literature in 1640, meaning "the act of conforming, acquiescing, or yelding, ... in a weak and subservient way". In medicine, compliance indicates "the extent to which the patient's behaviour matches the prescriber's recommendations" [2]. Compliance has been criticized for its paternalistic and authoritarian meaning, implying that the subject passively "obeys" a clinician's orders. In contrast, the word "adherence" appeared in 1530, with the meaning of "the quality of adherence, a steady devotion...", and in medicine, adherence is defined as "the extent to which the patient's behaviour matches agreed recommendations from the prescriber" [3], emphasizing just the free agreement of the patient to medical prescriptions from the doctor. Finally, the word "concordance" only appeared in 1997 and refers to the extent to which patients are successfully involved in shared decision making about their therapy $[4,5]$. Concordance means "therapeutic alliance", "partnership", a way to share information and agreed solutions between the patient and their healthcare provider.

Whereas compliance and adherence are relatively easy to measure, through several direct (observation, biological markers testing) or indirect (questionnaires, self-reports, diaries, anthropometric measures) tools, concordance is hard to quantify and cannot be empirically tested. It is often determined by the patient-doctor relationship in the light of their mutual knowledge, trust and attitude [6].

A cornerstone of long-life treatment of patients with advanced chronic kidney disease (CKD) is low protein diet (LPD), characterized by a protein intake of 0.6 to $0.2 \mathrm{~g}$ per kilogram of body weight per day, vegetable-enriched and sodium and phosphorus-depleted [7]. LPD is a safe and low-cost therapy, controls uremic symptoms and toxins generation, delays the progression to end stage kidney disease and seems to increase patients' survival [8-11].

Uremic syndrome is a condition characterized both by a dysbiotic gut microbiota and accelerated atherosclerosis. The intestinal microbiota of CKD patients is characterized by the shift from saccharolytic species to proteolytic ones, which contribute to the generation of several toxins $[12,13]$. The most studied microbial-derived toxins are $\mathrm{p}$-Cresyl Sulphate (PCS), derived from liver sulphatation of tyrosine and phenylalanine phenolic metabolites, and Indoxyl-Sulphate (IS), derived from liver sulphatation of tryptophan metabolite [12]. Both PCS and IS have been correlated with the progression of renal failure and cardiovascular morbidity and mortality in CKD [14-16]. The accelerated atherosclerosis is due to several mechanisms, among them Lipoprotein-associated phospholipase $\mathrm{A}_{2}$ (Lp-PLA ${ }_{2}$ ) plays a pivotal role. Lp-PLA ${ }_{2}$, a serine lipase produced by activated monocytes and macrophages, enters the vessel wall, catalyses the hydrolysis of LDLs phospholipids, induces the chemotaxis of leucocytes into the sub-intimal space and, eventually, contributes to the atherosclerotic plaque instability [17]. As matter of fact, Lp-PLA 2 predicts acute cardiovascular events $[18,19]$.

In this context, there are two important challenges in nephrology clinical practice: first, to determine whether an LPD could modulate the dysbiotic microbiota and atherogenic lipid profile and reduce uremic toxins in CKD patients and, second, how to verify whether patients follow renal nutritional prescriptions.

The aim of this study was, first, to assess and compare compliance, adherence and concordance among patients with advanced CKD on LPD and, second, to evaluate the impact of compliance, adherence and concordance on the reduction of the traditional, gut-derived and proatherogenic serum toxins.

\section{Patients and Methods}

\subsection{Participants}

Adult patients with advanced CKD not on dialysis (i.e., an estimated glomerular filtration rate (eGFR) between 6 and $25 \mathrm{~mL} / \mathrm{min} / 1.73 \mathrm{~m}^{2}$ ) afferent to the outpatient's ambulatory division of Nephrology and Dialysis at Maggiore della Carità Hospital in 
Novara were eligible. Patients refusing to sign the informed consent or refusing LPD were excluded.

\subsection{Intervention}

Low protein diet composition: proteins $0.6 \mathrm{~g} / \mathrm{kg}$ of "target" body weight/day, energy intake $25-30 \mathrm{kcal} / \mathrm{kg} /$ day, salt less than $6 \mathrm{~g} /$ day, phosphorus load less than $800 \mathrm{mg} /$ day, low content of saturated fats and cholesterol, high content of fibres; calcium, vitamin D, folic acid, vitamin B12, iron, erythropoietin supplementation according to the usual clinical indications and good clinical practices [7]. Free-protein products were prescribed when needed.

Compliance to the diet was directly tested through $24 \mathrm{~h}$ urine collection in order to measure total urine nitrogen (TUN) excretion according to the Maroni-Mitch formula [20]:

$$
\text { TUN }=\text { urine urea }(\mathrm{g} / \text { day })+0.031 \times \text { body weight },
$$

protein Catabolic Rate (PCR) according to the formula:

$$
\mathrm{PCR}=6.25 \times \mathrm{TUN}(\mathrm{g} / \text { day })
$$

and the total urine sodium excretion.

Adherence to the diet was verified by a trained dietitian by means of the dietary journal and through a dietary interview $(24 \mathrm{~h}$ recall). The dietician calculated the proteincaloric intake and determined the discrepancy with the prescribed regimen. A difference greater than $30 \%$ was considered not adherence. The 30\% threshold was arbitrarily chosen according to clinical experience and everyday practice.

Compliance to the diet was verified by a nephrologist through informal questions on prescribed drugs and nutritional therapy and knowledge about their contents and acknowledgement about mistakes or inobservance: a positive (concordant) or negative (no concordant) evaluation was assigned.

In order to motivate patients, during the first consultation, they were taught about the metabolic alterations secondary to advanced kidney disease and the effects of high protein intake on metabolic parameters and glomerular function. As a consequence, the potential benefits of an LPD were also discussed. Moreover, patients were instructed on how to weigh, cook and season food. In the following consultations, the nephrologist and the dietician posed some questions about the knowledge and the comprehension the patient had about the role of LPD in managing kidney disease. In particular, the examiner explored whether the patients understood why an LPD was proposed; the effect of LPD on bicarbonates, phosphates and CKD progression; and the willingness of the patient to pursue the low-protein regimen for their own benefit. Moreover, patients were asked about the effects of fibres in the diet and reassured about electrolyte imbalances (i.e., potassium intake). According to patient's answers, arbitrarily, the trained evaluator was able to assign the patient to a group.

Biochemical parameters and nutritional assessment were compared between adherent/not adherent and concordant/not concordant patients.

\subsection{Study Design}

At enrolment (T0) and after two months (T2), routinary laboratory measurements (haemoglobin, urea, creatinine, estimated glomerular filtration rate (eGFR) according to the CKD-EPI equation [21], sodium, potassium, uric acid, calcium, phosphate, parathyroid hormone (PTH), bicarbonates and albumin) were measured on an ADVIA ${ }^{\circledR} 1800$ Clinical Chemistry Analyzer (Siemens Healthcare Diagnostics, Munich, Germany); total and free serum p-Cresyl Sulphate (t- and f-PCS, respectively) and total and free serum Indoxyl Sulphate ( $\mathrm{t}$ - and $\mathrm{f}-\mathrm{IS}$, respectively) were measured by means of a high-performance liquid chromatography technique coupled with tandem mass spectrometry (B.S.N. Srl, 
Castelleone, Italy); serum Lp-PLA 2 activity was measured with the new PLAC ${ }^{\circledR}$ test (Diazyme Laboratories, Inc., 12889 Gregg Court, Poway, CA, USA).

Nutritional status was assessed by physical examination, measuring body weight, height, BMI $\left(\mathrm{kg} / \mathrm{m}^{2}\right)$, dominant Hand Grip strength $(\mathrm{kg})$ using Hydraulic Hand Dynamometer Owner's Manual (Sammons Preston, Bolingbrook, IL, USA), according to the reference values [22,23]. Bioelectrical impedance analysis (BIA) was used to estimate fat-free body mass $(\mathrm{kg})$, fat mass $(\mathrm{kg})$ and phase angle through an Akern model 101 (Akern Srl, Pisa, Italy).

\subsection{Statistical Analysis}

Statistical analyses were performed with the SPSS statistical software v.17.0 (SPSS Inc., Chicago, IL, USA) and R Language v.4.0.3 (R Foundation for Statistical Computing, Vienna, Austria). Normal distribution was preliminarily assessed by q-q plot and ShapiroWilk tests. Quantitative variables were expressed as mean and standard deviation while qualitative variables as absolute values and relative frequencies. Differences between groups for continuous variables were estimated by nonparametric Mann-Whitney U-test (for independent samples) and Wilcoxon Signed Ranks Test (for paired samples) or by parametric paired T-test. Concordance was verified by concordant pairs and Cohen's kappa. A $p<0.05$ was considered statistically significant.

\section{Results}

A total of 87 patients were assessed for eligibility: 27 were excluded (8 refused LPD, 7 refused to sign the informed consent, 12 did not satisfy the clinical criteria), 60 were enrolled and 57 subjects received the T2-evaluation ( 1 patient died and 2 patients were lost to follow-up). The mean age was $63.9 \pm 11.8$ years, $70 \%$ were males, $89 \%$ had arterial hypertension, $28 \%$ type II diabetes mellitus and $16 \%$ coronary artery disease

After 2 months of LPD, a significant reduction in BUN, total cholesterol and triglycerides was observed, without any difference with respect to the other biochemical and physical parameters. TUN and nPCR significantly decreased, according to the compliance to the diet (Table 1).

According to the dietitian's interview, $41(72 \%)$ patients resulted in being adherent to the diet, while, according to the nephrologist's opinion, 34 (59\%) patients were concordant with the nutritional therapy. Moreover, $30(52 \%)$ and $11(19 \%)$ patients received a positive and negative evaluation, respectively, from both the nephrologist and dietitian, with 73\% being concordant pairs and a Cohen's Kappa of 0.45 , demonstrating a fair concordance.

\subsection{Adherence Group}

At T2, in comparison with T0, adherent patients showed reduced levels of nPCR, BUN, total cholesterol, triglycerides, LDL-Cholesterol, f-PC and f-IS and increased bicarbonates, while non-adherent subjects showed a statistical reduction in albumin levels (Table 2).

\subsection{Concordance Group}

At T2, in comparison with T0, concordant patients showed reduced levels of nPCR, BUN, total cholesterol, LDL-Cholesterol, Lp-PLA2, t-PC, f-PC and t-IS and increased bicarbonates. In contrast, non-concordant subjects showed increased levels of Lp-PLA2 and t-PC (Table 3). 
Table 1. Comparison between biochemical and nutritional parameters and pharmacological therapy in all patients.

\begin{tabular}{|c|c|c|c|}
\hline & T0 & T2 & $p$ \\
\hline EPI-CKD (mL/min) & $18.1 \pm 3.7$ & $18.2 \pm 4.7$ & 0.77 \\
\hline Daily urine proteins (g/24 h) & $1.58 \pm 1.38$ & $1.74 \pm 1.96$ & 0.31 \\
\hline Hemoglobin (g/dL) & $12.0 \pm 1.5$ & $11.9 \pm 1.5$ & 0.08 \\
\hline BUN (mg/dL) & $52 \pm 17$ & $46 \pm 15$ & 0.007 \\
\hline Uric acid (mg/dL) & $6 \pm 1.4$ & $6 \pm 1.2$ & 0.49 \\
\hline Albumin (mg/dL) & $4.2 \pm 0.3$ & $4.1 \pm 0.3$ & 0.07 \\
\hline Calcium (mg/dL) & $9.1 \pm 0.5$ & $9.1 \pm 0.5$ & 0.19 \\
\hline Phosphorus (mg/dL) & $3.7 \pm 0.7$ & $3.7 \pm 0.8$ & 0.59 \\
\hline Total cholesterol (mg/dL) & $186 \pm 42$ & $161 \pm 70$ & 0.004 \\
\hline HDL (mg/dL) & $45 \pm 13$ & $45 \pm 13$ & 0.50 \\
\hline Triglycerides $(\mathrm{mg} / \mathrm{dL})$ & $196 \pm 151$ & $161 \pm 70$ & 0.037 \\
\hline $\mathrm{LDL}(\mathrm{mg} / \mathrm{dL})$ & $105 \pm 37$ & $94 \pm 30$ & 0.09 \\
\hline $\mathrm{HCO}_{3}(\mathrm{mEq} / \mathrm{L})$ & $22.6 \pm 3.2$ & $23.6 \pm 2.6$ & 0.001 \\
\hline PTH (ng/mL) & $92.9 \pm 76.4$ & $97.5 \pm 57.9$ & 0.08 \\
\hline Urine Natrium (mEq/day) & $144 \pm 59$ & $145 \pm 60$ & 0.47 \\
\hline Epoetin rensponse index $(\mathrm{IU} / \mathrm{gHb})$ & $134 \pm 345$ & $124 \pm 324$ & 0.79 \\
\hline Epoetin zeta (IU/week) & $1368 \pm 3410$ & $1280 \pm 3143$ & 0.81 \\
\hline Furosemide (mg/day) & $38.2 \pm 69.9$ & $30.7 \pm 45.5$ & 0.41 \\
\hline TUN g/kg/24 h & $10.9 \pm 3.5$ & $9.5 \pm 2.7$ & 0.0001 \\
\hline nPCR (g/kg/day) & $0.91 \pm 0.3$ & $0.77 \pm 0.2$ & 0.005 \\
\hline Lp-PLA $2(\mathrm{nmol} / \mathrm{mL} / \mathrm{min})$ & $165.5 \pm 44.4$ & $161.1 \pm 45.8$ & 0.52 \\
\hline $\mathrm{t}-\mathrm{PC}(\mathrm{mcMol})$ & $135.3 \pm 78.4$ & $120.4 \pm 69.8$ & 0.35 \\
\hline f-PC (mcMol) & $5.21 \pm 3.89$ & $4.2 \pm 3.1$ & 0.08 \\
\hline t-IS (mcMol) & $30.5 \pm 14.6$ & $28.4 \pm 14.4$ & 0.16 \\
\hline f-IS (mcMol) & $1.44 \pm 0.82$ & $1.35 \pm 0.99$ & 0.52 \\
\hline BMI $\left(\mathrm{kg} / \mathrm{cm}^{2}\right)$ & $29.4 \pm 8.3$ & $29.3 \pm 8.5$ & 0.38 \\
\hline Free Fat Mass (kg) & $52.7 \pm 11.8$ & $52.7 \pm 11.5$ & 0.99 \\
\hline Fat Mass (kg) & $23.7 \pm 8.4$ & $23.3 \pm 8.7$ & 0.31 \\
\hline Angle Phase & $4.89 \pm 1.11$ & $4.80 \pm 1.90$ & 0.23 \\
\hline Hand Grip (kg) & $33.8 \pm 10.4$ & $34.6 \pm 10.3$ & 0.15 \\
\hline
\end{tabular}

In bold, significant values. 
Table 2. Comparison between biochemical and nutritional parameters and pharmacological therapy in non-adherent and adherent patients.

\begin{tabular}{|c|c|c|c|c|c|c|}
\hline & \multicolumn{3}{|c|}{ Non-Adherent } & \multicolumn{3}{|c|}{ Adherent } \\
\hline & T0 & T2 & $p$ & T0 & $\mathrm{T} 2$ & $p$ \\
\hline EPI-CKD (mL/min) & $16.6 \pm 3.2$ & $16.5 \pm 4.6$ & 0.86 & $18.6 \pm 3.8$ & $19.0 \pm 4.6$ & 0.53 \\
\hline Daily urine proteins (g/24 h) & $1.9 \pm 1.3$ & $2.0 \pm 2.1$ & 0.66 & $1.5 \pm 1.4$ & $1.9 \pm 1.9$ & 0.26 \\
\hline Hemoglobin $(\mathrm{g} / \mathrm{dL})$ & $11.4 \pm 1.0$ & $11.2 \pm 1.2$ & 0.15 & $12.2 \pm 1.7$ & $12.1 \pm 1.5$ & 0.18 \\
\hline BUN (mg/dL) & $58 \pm 23$ & $52 \pm 18$ & 0.21 & $50 \pm 13$ & $44 \pm 14$ & 0.017 \\
\hline Uric acid (mg/dL) & $6.1 \pm 1.2$ & $6.0 \pm 1.1$ & 0.46 & $6.0 \pm 1.5$ & $6.0 \pm 1.3$ & 0.75 \\
\hline Albumin (mg/dL) & $4.2 \pm 0.3$ & $4.0 \pm 0.3$ & 0.04 & $4.3 \pm 0.4$ & $4.2 \pm 0.4$ & 0.37 \\
\hline Calcium (mg/dL) & $9.0 \pm 0.6$ & $8.9 \pm 0.5$ & 0.61 & $9.1 \pm 0.5$ & $9.1 \pm 0.6$ & 0.26 \\
\hline Phosphorus (mg/dL) & $3.7 \pm 0.7$ & $3.8 \pm 0.8$ & 0.75 & $3.6 \pm 0.7$ & $3.7 \pm 0.8$ & 0.79 \\
\hline Total cholesterol (mg/dL) & $183 \pm 61$ & $171 \pm 44$ & 0.61 & $186 \pm 34$ & $171 \pm 30$ & 0.002 \\
\hline HDL (mg/dL) & $47 \pm 13$ & $46 \pm 14$ & 0.28 & $45 \pm 14$ & $45 \pm 13$ & 0.99 \\
\hline Triglycerides (mg/dL) & $161 \pm 61$ & $151 \pm 42$ & 0.61 & $209 \pm 172$ & $165 \pm 79$ & 0.05 \\
\hline LDL (mg/dL) & $106 \pm 45$ & $94 \pm 34$ & 0.97 & $105 \pm 34$ & $94 \pm 29$ & 0.037 \\
\hline $\mathrm{HCO}_{3}(\mathrm{mEq} / \mathrm{L})$ & $23.0 \pm 2.7$ & $22.5 \pm 2.6$ & 0.63 & $22.4 \pm 3.4$ & $24.0 \pm 2.5$ & 0.0001 \\
\hline PTH (ng/mL) & $113.8 \pm 105.6$ & $104.8 \pm 58.9$ & 0.49 & $82.3 \pm 63.4$ & $94.2 \pm 59.0$ & 0.05 \\
\hline Urine Natrium (mEq/day) & $150 \pm 60$ & $148 \pm 47$ & 0.28 & $140 \pm 58$ & $144 \pm 65$ & 0.96 \\
\hline Epoetin response index (IU/gHb) & $71 \pm 196$ & $119 \pm 234$ & 0.49 & $160 \pm 368$ & $132 \pm 381$ & 0.41 \\
\hline Epoetin zeta (IU/week) & $800 \pm 2242$ & $1200 \pm 2306$ & 0.59 & $1609 \pm 3718$ & $1341 \pm 3449$ & 0.55 \\
\hline Furosemide (mg/day) & $50.0 \pm 81.3$ & $43.3 \pm 64.4$ & 0.25 & $34.7 \pm 66.7$ & $26.8 \pm 36.7$ & 0.78 \\
\hline nPCR (g/kg/day) & $0.82 \pm 0.33$ & $0.75 \pm 0.22$ & 0.15 & $0.93 \pm 0.28$ & $0.78 \pm 0.17$ & 0.003 \\
\hline Lp-PLA2 (nmol/mL/min) & $158.2 \pm 43.4$ & $161.0 \pm 54.1$ & 0.97 & $167.5 \pm 45.5$ & $159.98 \pm 42.9$ & 0.15 \\
\hline $\mathrm{t}-\mathrm{PC}(\mathrm{mcMol})$ & $173.6 \pm 90.2$ & $151.5 \pm 78.5$ & 0.92 & $123.8 \pm 71.1$ & $109.7 \pm 65.2$ & 0.15 \\
\hline f-PC (mcMol) & $7.49 \pm 5.63$ & $5.84 \pm 4.52$ & 0.86 & $4.51 \pm 2.81$ & $3.63 \pm 2.31$ & 0.04 \\
\hline $\mathrm{t}$-IS (mcMol) & $30.6 \pm 10.1$ & $30.2 \pm 15.7$ & 0.97 & $30.1 \pm 16.0$ & $27.9 \pm 14.3$ & 0.06 \\
\hline f-IS (mcMol) & $1.56 \pm 0.79$ & $1.51 \pm 1.10$ & 0.91 & $1.41 \pm 0.83$ & $1.31 \pm 0.97$ & 0.05 \\
\hline $\operatorname{BMI}\left(\mathrm{kg} / \mathrm{cm}^{2}\right)$ & $30.5 \pm 14.1$ & $30.6 \pm 14.4$ & 0.73 & $29.0 \pm 5.0$ & $28.9 \pm 5.0$ & 0.19 \\
\hline Free Fat Mass (kg) & $49.1 \pm 15.7$ & $49.4 \pm 16.0$ & 0.72 & $54.1 \pm 10.0$ & $53.9 \pm 9.3$ & 0.81 \\
\hline Fat Mass (kg) & $21.2 \pm 8.8$ & $20.4 \pm 9.0$ & 0.35 & $24.5 \pm 8.3$ & $24.3 \pm 8.5$ & 0.57 \\
\hline Angle Phase & $4.32 \pm 1.44$ & $4.29 \pm 1.45$ & 0.81 & $5.06 \pm 0.92$ & $4.98 \pm 0.88$ & 0.23 \\
\hline Hand Grip (kg) & $31.0 \pm 8.5$ & $33.1 \pm 9.6$ & 0.1 & $35.0 \pm 10.8$ & $35.1 \pm 10.6$ & 0.66 \\
\hline
\end{tabular}


Table 3. Comparison between biochemical and nutritional parameters and pharmacological therapy in non-concordant and concordant patients.

\begin{tabular}{|c|c|c|c|c|c|c|}
\hline & \multicolumn{3}{|c|}{ Non-Concordant } & \multicolumn{3}{|c|}{ Concordant } \\
\hline & T0 & T2 & $p$ & T0 & T2 & $p$ \\
\hline EPI-CKD (mL/min) & $18.1 \pm 2.9$ & $17.7 \pm 4.2$ & 0.64 & $18.8 \pm 4.2$ & $18.6 \pm 5.1$ & 0.52 \\
\hline Daily urine proteins (g/24 h) & $1.9 \pm 1.6$ & $2.0 \pm 2.3$ & 0.91 & $1.49 \pm 1.2$ & $2.7 \pm 2.4$ & 0.68 \\
\hline Hemoglobin (g/dL) & $11.7 \pm 1.4$ & $11.5 \pm 1.6$ & 0.34 & $12.2 \pm 1.6$ & $12.1 \pm 1.4$ & 0.12 \\
\hline BUN (mg/dL) & $52 \pm 20$ & $50 \pm 15$ & 0.85 & $52 \pm 14$ & $44 \pm 14$ & 0.003 \\
\hline Uric acid (mg/dL) & $6.4 \pm 1.1$ & $6.2 \pm 1.1$ & 0.28 & $5.8 \pm 1.5$ & $5.8 \pm 1.3$ & 0.99 \\
\hline Albumin (mg/dL) & $4.1 \pm 0.3$ & $4.1 \pm 0.3$ & 0.48 & $4.3 \pm 0.4$ & $4.2 \pm 0.4$ & 0.1 \\
\hline Calcium (mg/dL) & $8.9 \pm 0.6$ & $8.9 \pm 0.5$ & 0.96 & $9.2 \pm 0.6$ & $9.1 \pm 0.6$ & 0.13 \\
\hline Phosphorus (mg/dL) & $3.7 \pm 0.7$ & $3.8 \pm 0.8$ & 0.41 & $3.6 \pm 0.7$ & $3.6 \pm 0.9$ & 0.98 \\
\hline Total cholesterol (mg/dL) & $190 \pm 53$ & $177 \pm 41$ & 0.37 & $183 \pm 32$ & $167 \pm 29$ & 0.005 \\
\hline $\mathrm{HDL}(\mathrm{mg} / \mathrm{dL})$ & $46 \pm 15$ & $46 \pm 14$ & 0.6 & $45 \pm 12$ & $45 \pm 12$ & 0.8 \\
\hline Triglycerides (mg/dL) & $198 \pm 152$ & $160 \pm 53$ & 0.11 & $193 \pm 152$ & $162 \pm 80$ & 0.14 \\
\hline $\mathrm{LDL}(\mathrm{mg} / \mathrm{dL})$ & $106 \pm 47$ & $99 \pm 32$ & 0.97 & $104 \pm 30$ & $91 \pm 28$ & 0.03 \\
\hline $\mathrm{HCO}_{3}(\mathrm{mEq} / \mathrm{L})$ & $22.6 \pm 2.9$ & $23.2 \pm 2.9$ & 0.18 & $22.6 \pm 3.4$ & $23.9 \pm 2.5$ & 0.006 \\
\hline PTH (ng/mL) & $107.8 \pm 87.8$ & $104.8 \pm 58.9$ & 0.18 & $82.9 \pm 67.1$ & $93 \pm 57.6$ & 0.19 \\
\hline Urine Natrium (mEq/day) & $164 \pm 69$ & $165 \pm 56$ & 0.92 & $133 \pm 49$ & $132 \pm 55$ & 0.37 \\
\hline Epoetin response index (IU/gHb) & $150 \pm 277$ & $189 \pm 455$ & 0.78 & $160 \pm 388$ & $132 \pm 361$ & 0.49 \\
\hline Epoetin zeta (IU/week) & $1608 \pm 2965$ & $1869 \pm 4267$ & 0.71 & $1205 \pm 3715$ & $882 \pm 2056$ & 0.46 \\
\hline Furosemide (mg/day) & $38.0 \pm 69.8$ & $39.1 \pm 57.9$ & 0.79 & $38.2 \pm 71.3$ & $25.0 \pm 34.7$ & 0.19 \\
\hline nPCR (g/kg/day) & $0.87 \pm 0.27$ & $0.81 \pm 0.21$ & 0.22 & $0.93 \pm 0.32$ & $0.74 \pm 0.19$ & 0.002 \\
\hline Lp-PLA2 (nmol/mL/min) & $175.6 \pm 48.1$ & $182.3 \pm 48.6$ & 0.019 & $158.9 \pm 41.4$ & $146.8 \pm 38.2$ & 0.013 \\
\hline t-PC (mcMol) & $133.1 \pm 79.1$ & $141.1 \pm 66.7$ & 0.005 & $136.7 \pm 79.1$ & $106.9 \pm 69.5$ & 0.001 \\
\hline f-PC (mcMol) & $5.32 \pm 4.46$ & $4.84 \pm 3.57$ & 0.29 & $5.13 \pm 3.53$ & $3.77 \pm 2.91$ & 0.003 \\
\hline t-IS (mcMol) & $29.4 \pm 13.4$ & $29.4 \pm 13.3$ & 0.32 & $31.2 \pm 15.5$ & $27.7 \pm 15.5$ & 0.021 \\
\hline f-IS (mcMol) & $1.39 \pm 0.64$ & $1.23 \pm 0.57$ & 0.70 & $1.46 \pm 0.92$ & $1.43 \pm 1.19$ & 0.09 \\
\hline $\operatorname{BMI}\left(\mathrm{kg} / \mathrm{cm}^{2}\right)$ & $28.3 \pm 3.9$ & $28.4 \pm 3.9$ & 0.91 & $30.1 \pm 10.2$ & $29.9 \pm 10.4$ & 0.29 \\
\hline Free Fat Mass (kg) & $54.4 \pm 10.4$ & $54.9 \pm 10.2$ & 0.31 & $51.7 \pm 12.7$ & $51.3 \pm 12.2$ & 0.28 \\
\hline Fat Mass (kg) & $24.5 \pm 7.6$ & $24.2 \pm 6.7$ & 0.54 & $23.7 \pm 8.1$ & $2.4 \pm 9.2$ & 0.41 \\
\hline Angle Phase & $4.68 \pm 0.85$ & $4.71 \pm 0.93$ & 0.85 & $5.14 \pm 0.90$ & $5.00 \pm 0.85$ & 0.11 \\
\hline Hand Grip (kg) & $31.5 \pm 3.6$ & $31.8 \pm 4.2$ & 0.21 & $32.1 \pm 4.2$ & $31.5 \pm 4.5$ & 0.49 \\
\hline
\end{tabular}

In bold, significant values.

\subsection{Changes in Nutritional Status}

Enrolled patients had, on average, a good nutritional status and no significant variations were observed in both adherent and concordant groups (Tables 2 and 3 ).

\section{Discussion}

This study demonstrates that LPD reduces blood urea nitrogen, cholesterol and triglycerides and increases bicarbonates in all compliant patients that LPD reduces t-PC and T-IS in "adherent" ones and, finally, that LPD reduces gut-derived toxins ( $t-P C, f-P C, t-I S$ ) and Llp-PLA 2 in "concordant" patients, whereas an increased burden of uremic toxins was observed among non-concordant patients. This is in accordance with the literature, 
where every reduction of $0.2 \mathrm{~g} / \mathrm{kg}$ of daily protein intake improves the progression of renal disease, independently on the initial values [24].

Protein-restricted diets are known to have an important role in reducing "traditional" uremic toxins responsible for uremic symptoms, such as ammonium solutes, controlling calcium-phosphorus metabolism alterations, sodium and water retention and electrolytes imbalances. An LPD also counteracts the endogenous protein catabolism and malnutrition, delays the progression to end-stage kidney disease and dialysis initiation and seems to improve the survival of CKD patients $[8-11,25,26]$.

At the intestinal level, LPD is able to modulate the dysbiotic microbiota through several mechanisms: first, the reduction in animal proteins and amino acid intake limits the availability of substrates for proteolytic bacteria; second, the high content of vegetables, legumes, fibers and whole grains that are rich in prebiotics promotes the restoration of the saccharolytic pathway over the proteolytic one $[27,28]$. As largely discussed by Camerotto and colleagues, an LPD is characterized by a high content of fibers, on average $7.6 \mathrm{~g} / 1000 \mathrm{Kcal}$ for a traditional LPD, up to $11.6 \mathrm{~g} / 1000 \mathrm{Kcal}$ for a very-LPD or $16 \mathrm{~g} / 1000 \mathrm{Kcal}$ for a vegan LPD [29]. Protein-free products contain much more fibers than regular products: 4.8 vs. $2.7 \mathrm{~g} / 100 \mathrm{~g}$ in protein-free and regular pasta, respectively, and 10.8 vs. $2.7 \mathrm{~g} / 100 \mathrm{~g}$ in protein-free and regular bread, respectively [29]. Moreover, in more recent years, protein-free products are even more enriched with fibers, fructooligosaccharides, galactooligosaccharides, inulin and mannans, with an increased mean content from 4.2 to $10.8 \mathrm{~g} / 100 \mathrm{~g}$ and from 1.5 to $4.8 \mathrm{~g} / 100 \mathrm{~g}$ in bread and pasta, respectively [29]. As a matter of fact, Black et al. observed a reduction in PCS in CKD subjects after 6 months of LPD, while Marzocco et al. found a reduction in IS levels among CKD subjects after only 1 week of very low protein diet [30,31]. According to these findings, we observed a reduction in PCS and IS in adherent and concordant subjects.

In the present trial, an LPD also reduced Lp-PLA $A_{2}$ serum levels. Previous studies demonstrated that plant-based diets reduce the atherogenic lipid levels in the general population and, in particular, Lp-PLA 2 [32-34]. However, although we could not ascertain the direct relationship between an LPD and Lp-PLA , our study is the first to show a possible benefit of an LPD in reducing Lp-PLA ${ }_{2}$ levels in patients with advanced renal failure. Lp-PLA $A_{2}$ is an emergent proatherogenic molecule, predicting cardiovascular disease and mortality in the general population as well as in cardiac or diabetic patients, so that the three major heart international societies, the American Heart Association, the American College of Cardiology and the European Society of Cardiology, include the Lp-PLA 2 activity determination in the risk stratification charts in order to optimize the lipid lowering treatment [35]. Some evidences show that, in uremic subjects, serum Lp-PLA 2 values are elevated and predict acute cardiovascular events [36,37].

The main findings of this study are the differences observed in compliant, adherent and concordant patients: the deeper and more comprehensive the investigation is, the earlier and more accurate are the results. Adherence to the medical prescriptions is recognized to improve healthcare-related outcomes, and in the nephrology setting, poor dietary "adherence" is associated with worse outcomes [38,39]. Several studies investigated different tools for testing adherence to renal diets, such as objective (blood and urinary parameters) and subjective approaches (24-h or 3 day food recalls, food frequency questionnaires) or a combination of the two. Indeed, in our study, we used blood and urinary parameters to test "compliance" and the $24 \mathrm{~h}$ recalls were assessed by the dietitian to test "adherence".

As a consequence of the different definitions, the literature provides highly variable rates of adherence, ranging from about 9 to $50 \%$ [40]. However, we found even greater figures: $72 \%$ of subjects are recognized as "adherent", $59 \%$ as "concordant" and $52 \%$ received a positive judgment from both the dietitian and the nephrologists.

Among several factors associated with adherence, such as age, educational level and family support, the role of the "knowledge" is controversial with either positive or negative association, but the literature, in general, agrees that the patient "activation" and "engagement" are needed to ameliorate adherence [40-43]. Based on these considerations, in the 
present study, we tried to convert the subjective and unmeasurable concept of "concordance" into a semi-quantitative variable (presence/absence) in order to obtain objective results (variations in blood and urinary parameters). Concordance was judged by the nephrologist based on the mutual acquaintance with the patient because the quality of the relationship between the healthcare provider and the patient is recognized as an important modifier of therapy adherence [40]. Nevertheless, as well as for the nutritional and pharmacological prescription and for the feedback, the combined approach of nephrologists and dietitians is advisable because the multidisciplinary team care has been demonstrated to protect from the progression of renal disease [44].

The main limitation of this study is the low sample size and the short follow-up: Several larger controlled trials are needed to observe an eventual benefit on renal and patients' survival. Moreover, in addition to the terms "adherence" and "concordance", the term "persistence", describing the duration of continuous medication use, is becoming more and more important for patients with chronic diseases [45]. In this respect, nutritional therapy being a life-long therapy for CKD patients, regardless of the stage of kidney disease, dialysis or kidney-transplantation status, further studies are needed to assess persistence in the nutritional approach system of care.

In conclusion, the present study demonstrates that a comprehensive approach to evaluate compliance, adherence and concordance to an LPD in CKD patients is useful to monitor and predict nutritional interventions and timely adapt them to guarantee the persistence of the patients in the system of care. In the modern era of "personalized" medicine, and particularly in the context of more "personalized" renal diets, a "personalized" partnership between the doctor and the patient is also desirable in order to optimize the nutritional therapy outcomes.

Author Contributions: A.D.M.: conceptualization, data curation, formal analysis, investigation, methodology, supervision, writing — original draft, review and editing; D.C. (Deborah Carrera): conceptualization, supervision, data curation, investigation, review original draft; M.V.: supervision, statistical analysis, methodology, review original draft; M.B.: conceptualization, methodology, review original draft; R.R.: conceptualization, methodology, review original draft; S.R.: supervision, review original draft; M.T.: supervision, writing — original draft, review and editing; D.C. (Doriana Chiarinotti): supervision, review original draft. All authors have read and agreed to the published version of the manuscript.

Funding: This study received no funding. The article processing charges were supported by Schär AG/SPA, Winkelau 9, 39014 Burgstall (BZ), Italy.

Institutional Review Board Statement: The study was conducted in accordance with the Declaration of Helsinki (2000) of the World Medical Association. Data analyzed and described in the present paper belong to the study approved on 13 March 2017 by the Ethical Committee of Maggiore della Carità Hospital, Novara (215/CE n. CE 30 \17).

Informed Consent Statement: Written informed consent has been obtained from all enrolled patients.

Data Availability Statement: The data presented in this study are available on request from the corresponding author.

Conflicts of Interest: All the authors declare no conflict of interest.

\section{References}

1. De las Cuevas, C. Towards a clarification of terminology in medicine taking behavior: Compliance, adherence and concordance are related although different terms with different uses. Curr. Clin. Pharmacol. 2011, 6, 74-77. [CrossRef] [PubMed]

2. Haynes, R.B.; Taylor, D.W.; Sackett, D.L. Compliance in Health Care; Johns Hopkins University Press: Baltimore, MD, USA, 1979.

3. Barofsky, I. Compliance, adherence and the therapeutic alliance: Steps in the development of self-care. Soc. Sci. Med. 1978, 12, 369-376. [PubMed]

4. Royal Pharmaceutical Society of Great Britain; Marinker, M. From Compliance to Concordance: Achieving Shared Goals in Medicine Taking; Royal Pharmaceutical Society, in Partnership with Merck Sharp \& Dohme: London, UK, 1997.

5. Segal, J.Z. "Compliance" to "concordance": A critical view. J. Med. Humanit. 2007, 28, 81-96. [CrossRef] [PubMed]

6. Osterberg, L.; Blaschke, T. Adherence to medication. N. Engl. J. Med. 2005, 353, 487-497. [CrossRef] 
7. Ikizler, T.A.; Burrowes, J.D.; Byham-Gray, L.D.; Campbell, K.L.; Carrero, J.J.; Chan, W.; Fouque, D.; Friedman, A.N.; Ghaddar, S.; Goldstein-Fuchs, D.J.; et al. KDOQI Clinical Practice Guideline for Nutrition in CKD: 2020 Update. Am. J. Kidney Dis. 2020, 76, S1-S107. [CrossRef]

8. Piccoli, G.B.; Nazha, M.; Capizzi, I.; Vigotti, F.N.; Mongilardi, E.; Bilocati, M.; Avagnina, P.; Versino, E. Patient Survival and Costs on Moderately Restricted Low-Protein Diets in Advanced CKD: Equivalent Survival at Lower Costs? Nutrients 2016, 8, 758. [CrossRef]

9. Cupisti, A.; Brunori, G.; Di Iorio, B.R.; D’Alessandro, C.; Pasticci, F.; Cosola, C.; Bellizzi, V.; Bolasco, P.; Capitanini, A.; Fantuzzi, A.L.; et al. Nutritional treatment of advanced CKD: Twenty consensus statements. J. Nephrol. 2018, 31, 457-473. [CrossRef]

10. Cupisti, A.; Bolasco, P.; D'Alessandro, C.; Giannese, D.; Sabatino, A.; Fiaccadori, E. Protection of Residual Renal Function and Nutritional Treatment: First Step Strategy for Reduction of Uremic Toxins in End-Stage Kidney Disease Patients. Toxins 2021, 13, 289. [CrossRef]

11. Rysz, J.; Franczyk, B.; Cialkowska-Rysz, A.; Gluba-Brzozka, A. The Effect of Diet on the Survival of Patients with Chronic Kidney Disease. Nutrients 2017, 9, 495. [CrossRef]

12. Vaziri, N.D.; Wong, J.; Pahl, M.; Piceno, Y.M.; Yuan, J.; DeSantis, T.Z.; Ni, Z.; Nguyen, T.H.; Andersen, G.L. Chronic kidney disease alters intestinal microbial flora. Kidney Int. 2013, 83, 308-315. [CrossRef]

13. Mafra, D.; Lobo, J.C.; Barros, A.F.; Koppe, L.; Vaziri, N.D.; Fouque, D. Role of altered intestinal microbiota in systemic inflammation and cardiovascular disease in chronic kidney disease. Future Microbiol. 2014, 9, 399-410. [CrossRef] [PubMed]

14. Vanholder, R.; Schepers, E.; Pletinck, A.; Nagler, E.V.; Glorieux, G. The uremic toxicity of indoxyl sulfate and p-cresyl sulfate: A systematic review. J. Am. Soc. Nephrol. 2014, 25, 1897-1907. [CrossRef] [PubMed]

15. Lin, C.J.; Wu, V.; Wu, P.C.; Wu, C.J. Meta-Analysis of the Associations of p-Cresyl Sulfate (PCS) and Indoxyl Sulfate (IS) with Cardiovascular Events and All-Cause Mortality in Patients with Chronic Renal Failure. PLoS ONE 2015, 10, e0132589. [CrossRef] [PubMed]

16. Wu, I.W.; Hsu, K.H.; Lee, C.C.; Sun, C.Y.; Hsu, H.J.; Tsai, C.J.; Tzen, C.Y.; Wang, Y.C.; Lin, C.Y.; Wu, M.S. p-Cresyl sulphate and indoxyl sulphate predict progression of chronic kidney disease. Nephrol. Dial Transplant 2011, 26, 938-947. [CrossRef]

17. Cai, A.; Zheng, D.; Qiu, R.; Mai, W.; Zhou, Y. Lipoprotein-associated phospholipase A2 (Lp-PLA(2)): A novel and promising biomarker for cardiovascular risks assessment. Dis. Markers 2013, 34, 323-331. [CrossRef]

18. Li, D.; Zhao, L.; Yu, J.; Zhang, W.; Du, R.; Liu, X.; Liu, Y.; Chen, Y.; Zeng, R.; Cao, Y.; et al. Lipoprotein-associated phospholipase A2 in coronary heart disease: Review and meta-analysis. Clin. Chim. Acta 2017, 465, 22-29. [CrossRef]

19. Li, D.; Wei, W.; Ran, X.; Yu, J.; Li, H.; Zhao, L.; Zeng, H.; Cao, Y.; Zeng, Z.; Wan, Z. Lipoprotein-associated phospholipase A2 and risks of coronary heart disease and ischemic stroke in the general population: A systematic review and meta-analysis. Clin. Chim. Acta 2017, 471, 38-45. [CrossRef]

20. Maroni, B.J.; Steinman, T.I.; Mitch, W.E. A method for estimating nitrogen intake of patients with chronic renal failure. Kidney Int 1985, 27, 58-65. [CrossRef]

21. Levey, A.S.; Stevens, L.A.; Schmid, C.H.; Zhang, Y.L.; Castro, A.F., 3rd; Feldman, H.I.; Kusek, J.W.; Eggers, P.; Van Lente, F.; Greene, T.; et al. A new equation to estimate glomerular filtration rate. Ann. Intern Med. 2009, 150, 604-612. [CrossRef]

22. World Health Organization. Physical Status: The Use of and Interpretation of Anthropometry, Report of a WHO Expert Committee; World Health Organization: Geneva, Switzerland, 1995.

23. Frisancho, A.R. Anthropometric Standards for the Assessment of Growth and Nutritional Status; The University of Michigan Press: Ann Arbor, MI, USA, 1990.

24. Mitch, W.E.; Remuzzi, G. Diets for patients with chronic kidney disease, still worth prescribing. J. Am. Soc. Nephrol. 2004, 15, 234-237. [CrossRef]

25. Bellizzi, V.; Cupisti, A.; Locatelli, F.; Bolasco, P.; Brunori, G.; Cancarini, G.; Caria, S.; De Nicola, L.; Di Iorio, B.R.; Di Micco, L.; et al. Low-protein diets for chronic kidney disease patients: The Italian experience. BMC Nephrol. 2016, 17, 77. [CrossRef] [PubMed]

26. Ko, G.-J.; Kalantar-Zadeh, K. How important is dietary management in chronic kidney disease progression? A role for low protein diets. Korean J. Intern. Med. 2021, 36, 795-806. [CrossRef] [PubMed]

27. Koppe, L.; Fouque, D.; Soulage, C.O. The Role of Gut Microbiota and Diet on Uremic Retention Solutes Production in the Context of Chronic Kidney Disease. Toxins 2018, 10, 155. [CrossRef] [PubMed]

28. Mafra, D.; Borges, N.; Alvarenga, L.; Esgalhado, M.; Cardozo, L.; Lindholm, B.; Stenvinkel, P. Dietary Components That May Influence the Disturbed Gut Microbiota in Chronic Kidney Disease. Nutrients 2019, 11, 496. [CrossRef]

29. Camerotto, C.; Cupisti, A.; D'Alessandro, C.; Muzio, F.; Gallieni, M. Dietary Fiber and Gut Microbiota in Renal Diets. Nutrients 2019, 11, 2149. [CrossRef]

30. Black, A.P.; Anjos, J.S.; Cardozo, L.; Carmo, F.L.; Dolenga, C.J.; Nakao, L.S.; de Carvalho Ferreira, D.; Rosado, A.; Carraro Eduardo, J.C.; Mafra, D. Does Low-Protein Diet Influence the Uremic Toxin Serum Levels From the Gut Microbiota in Nondialysis Chronic Kidney Disease Patients? J. Ren. Nutr. 2018, 28, 208-214. [CrossRef]

31. Marzocco, S.; Dal Piaz, F.; Di Micco, L.; Torraca, S.; Sirico, M.L.; Tartaglia, D.; Autore, G.; Di Iorio, B. Very low protein diet reduces indoxyl sulfate levels in chronic kidney disease. Blood Purif. 2013, 35, 196-201. [CrossRef]

32. Dinu, M.; Abbate, R.; Gensini, G.F.; Casini, A.; Sofi, F. Vegetarian, vegan diets and multiple health outcomes: A systematic review with meta-analysis of observational studies. Crit. Rev. Food Sci. Nutr. 2017, 57, 3640-3649. [CrossRef] 
33. Yokoyama, Y.; Levin, S.M.; Barnard, N.D. Association between plant-based diets and plasma lipids: A systematic review and meta-analysis. Nutr. Rev. 2017, 75, 683-698. [CrossRef]

34. Najjar, R.S.; Moore, C.E.; Montgomery, B.D. Consumption of a defined, plant-based diet reduces lipoprotein(a), inflammation, and other atherogenic lipoproteins and particles within 4 weeks. Clin. Cardiol. 2018, 41, 1062-1068. [CrossRef]

35. Davidson, M.H.; Corson, M.A.; Alberts, M.J.; Anderson, J.L.; Gorelick, P.B.; Jones, P.H.; Lerman, A.; McConnell, J.P.; Weintraub, H.S. Consensus panel recommendation for incorporating lipoprotein-associated phospholipase A2 testing into cardiovascular disease risk assessment guidelines. Am. J. Cardiol. 2008, 101, 51F-57F. [CrossRef]

36. Rolla, R.; De Mauri, A.; Valsesia, A.; Vidali, M.; Chiarinotti, D.; Bellomo, G. Lipoprotein profile, lipoprotein-associated phospholipase A2 and cardiovascular risk in hemodialysis patients. J. Nephrol. 2015, 28, 749-755. [CrossRef] [PubMed]

37. De Mauri, A.; Vidali, M.; Chiarinotti, D.; Bellomo, G.; Rolla, R. Lipoprotein-associated phospholipase A2 predicts cardiovascular events in dialyzed patients. J. Nephrol. 2019, 32, 283-288. [CrossRef] [PubMed]

38. van Dulmen, S.; Sluijs, E.; van Dijk, L.; de Ridder, D.; Heerdink, R.; Bensing, J. Patient adherence to medical treatment: A review of reviews. BMC Health Serv. Res. 2007, 7, 55. [CrossRef] [PubMed]

39. Desroches, S.; Lapointe, A.; Ratte, S.; Gravel, K.; Legare, F.; Turcotte, S. Interventions to enhance adherence to dietary advice for preventing and managing chronic diseases in adults. Cochrane Database Syst. Rev. 2013, 2. [CrossRef]

40. Lambert, K.; Mullan, J.; Mansfield, K. An integrative review of the methodology and findings regarding dietary adherence in end stage kidney disease. BMC Nephrol. 2017, 18, 318. [CrossRef]

41. Hollingdale, R.; Sutton, D.; Hart, K. Facilitating dietary change in renal disease: Investigating patients' perspectives. J. Ren. Care 2008, 34, 136-142. [CrossRef]

42. Hibbard, J.H.; Cunningham, P.J. How engaged are consumers in their health and health care, and why does it matter? Res. Brief 2008, 8, 1-9.

43. Hibbard, J.H.; Greene, J. What the evidence shows about patient activation: Better health outcomes and care experiences; fewer data on costs. Health Aff. 2013, 32, 207-214. [CrossRef]

44. Bayliss, E.A.; Bhardwaja, B.; Ross, C.; Beck, A.; Lanese, D.M. Multidisciplinary team care may slow the rate of decline in renal function. Clin. J. Am. Soc. Nephrol. 2011, 6, 704-710. [CrossRef]

45. Fraser, S. Concordance, compliance, preference or adherence. Patient Prefer. Adherence 2010, 4, 95-96. [CrossRef] [PubMed] 